\title{
artículos
}

\section{El obispo de Málaga Luis Fernández de Córdoba y el retablo mayor del templo parroquial de Guadalcázar}

\author{
Sarai Herrera Pérez \\ Universidad de Jaén
}

\section{RESUMEN}

El siguiente artículo pretende analizar la interesante personalidad de Luis Fernández de Córdoba y Portocarrero mediante el encargo del retablo mayor que, el obispo de la diócesis de Málaga, realiza con destino a la parroquia de Guadalcázar, núcleo territorial del poder de su linaje.

PALABRAS CLAVE: Luis Fernández de Córdoba y Portocarrero/ Guadalcazar/ Retablo mayor.

The bishop of Malaga Luis Fernandez of Cordova and the major altarpiece of Guadalcazar's parochial temple

ABSTRACT

The following article tries to analyze Luis' Fernandez interesting personality of Cordova and Portocarrero by means of the order of the major altarpiece that, the bishop of the diocese of Malaga, realizes with destination to the parish of Guadalcazar, territorial core of the power of his linage. Major altarpiece.

KEY WORDS: Luis Fernandez of Cordova and Portocarrero/ Guadalcazar/

Luis Fernández de Córdoba y Portocarrero ${ }^{1}$ nace en la capital cordobesa en febrero del año 1555. Fue hijo del VIII señor de Guadalcázar, don Antonio Fernández de Córdoba, y de doña Brianda Portocarrero de Mendoza, dama natural de Écija y nieta del primer conde de Palma del Río. Asimismo, fue sobrino del obispo de Badajoz, don Andrés Fernández de Córdoba y Carvajal, y tío de don Diego Fernández de Córdoba, primer marqués de Guadalcázar que llegaría a ostentar la titularidad de los virreinatos de Nueva España y del Perú, respectivamente. Por todo ello, sin lugar a dudas, nos encontramos ante una personalidad nada desdeñable que se desarrolla en un ámbito familiar de prestigio.

Nuestro personaje iniciaría, a los once años de edad, sus estudios en la Universidad de Salamanca, en la que obtendría el doctorado en Derecho Civil y Canónico. Posteriormente se traslada a Roma, donde prolonga su estancia hasta el

* HERRERA PÉREZ, Sarai: "El obispo de Málaga Luis Fernández de Córdoba y el retablo mayor del templo parroquial de Guadalcázar", en Boletín de Arte n 32-33, Departamento de Historia del Arte, Universidad de Málaga, 2011-2012, págs. 331-337. Fecha de recepción: Junio de 2010.

1 Para obtener una visión global y precisa de este miembro del linaje véase AGUAYO EGIDO, Francisco: "EI arzobispo Luis Fernández de Córdoba" en AA.VV.: Actas del XX Congreso Nacional de Cronistas Españoles y XXV Reunión Anual de Cronistas Cordobeses. Córdoba, Asociación Española de Cronistas oficiales, 1997, pp. 137-149. 
momento en el que el pontífice Gregorio XIII lo designa deán de la Catedral cordobesa². Posteriormente, en el 1602, el monarca Felipe III, en atención a sus cualidades y virtudes lo propone para presidir la sede episcopal salmantina, ejercicio que hace que las fuentes lo describan como una persona "eminente en el gouierno, y buen exemplo de vida. Dio por su mano despacho a todos los negocios de sus súbditos, y assí tenía de todos cumplida noticia. En las prouisiones de los Beneficios curados estuuo tan atento, que premió siempre al Virtuoso, y Letrado"3.

Sin embargo, el 9 de febrero de 1613 recibiría el nombramiento como obispo malagueño ${ }^{4}$. En esta ocasión, don Fernando de Mena, arcediano de Carrión y canónigo de Palencia, sería el responsable de tomar posesión de la silla episcopal en su nombre, en un acto que fue celebrado el día 11 de mayo de 1615. Don Luis Fernández de Córdoba ya se encontraba residiendo en la capital malacitana a finales de año, puesto que preside el cabildo que se celebra el 2 de diciembre, dónde expresa tanto su deseo de socorrer a los niños expósitos como de visitar la Santa Iglesia Catedral, con el objeto de conocer aquellos elementos que precisaran de reforma ${ }^{5}$.

Su labor caritativa también fue dirigida hacia los pobres de la cárcel, a los que mejora sus condiciones de habitabilidad e incluso libera, si ello fuera posible. A la vez, financió una casa de recogida de mujeres con la finalidad de procurarles el sustento necesario. También, a lo largo del desarrollo de su cargo, se preocupó en conocer y visitar personalmente cada una de las instituciones que conformaban su obispado. Pero, de todos modos, su trayectoria eclesiástica no se detendría aquí, sino que alcanzaría elevadas cotas de poder al desempeñar la labor de arzobispo de Santiago de Compostela ${ }^{6}$, a partir del 23 de mayo de 1624, para poco después hacer lo propio en la sede de Sevilla7.

De cualquier manera, nuestra atención tiene que centrarse en su etapa como obispo de Málaga, momento al que se adscriben numerosas empresas artísticas que se desarrollan bajo su patrocinio. Entre ellas, sin lugar a dudas, destaca el frontal de altar de la Catedral, pero también el encargo que acomete con destino a la villa cordobesa de Guadalcázar. Nos referimos, en este sentido, al retablo mayor de la parroquia de Nuestra Señora de Gracia [1], que sería ejecutado en el período que comprende desde el año 1616 al $1620^{8}$.

2 Sucede a don Alonso Fernández de Córdoba, siendo el cuarto miembro del linaje que ocupa este cargo.

3 GÓNZALEZ DÁVILA, Gil: Teatro eclesiástico de las Iglesias Metropolitanas y Catedrales de los Reynos de las dos Castillas. Vidas de sus Arzobispos, y Obispos, y cosas memorables de sus sedes. Madrid, Imprenta de Pedro de Horna, 1650, fol. 357.

4 Para conocer diversos aspectos de la diócesis de Málaga véase MONDÉJAR CUMPIÁN, Francisco: Obispos de la Iglesia de Málaga. Córdoba, Obra Social y Cultural de Cajasur, 1998.

5 ACCM: Actas Capitulares, n. ${ }^{\circ} 19$, f. 20 vto.

6 BARREIRO MALLÓN, Baudilio: "Iglesias de Santiago de Compostela y Tuy-Vigo" en AA.VV.: Historia de las diócesis españolas, vol. 14. Madrid, Editorial Biblioteca Autores Cristianos, 2002, p. 223.

7 El 12 de marzo de 1624 se efectúa, en Roma, su nombramiento como titular del arzobispado de Sevilla. La toma de posesión fue realizada, el 23 de mayo, por Francisco de Monsalve, deán de la iglesia patriarcal, que sucedió en el cargo a otro ilustre varón de la Casa de los Córdobas, Diego Fernández de Córdoba y Lasso de Castilla. La entrada en Sevilla de don Luis Fernández de Córdoba se produjo el día 5 de julio, siendo recibido con júbilo por los dos cabildos de la ciudad, en el exterior de su recinto amurallado. El desempeño de este cargo sería muy breve, ya que el 26 de junio de 1625 le sorprende la muerte.

Algunos datos que describen su arzobispado se recogen en ORTÍZ DE ZÚÑIGA, Diego: Anales eclesiásticos y secvlares de la Muy Noble y muy leal Civdad de Seuilla. Madrid, Imprenta Real, 1646, p. 310.

8 AROCA LARA, Ángel: "La escultura cordobesa del Seiscientos" en Antonio del Castillo y su época, catálogo 
En este aspecto, debemos considerar que el retablo, en el contexto de producción artística de este momento, no sólo contribuye a otorgar un mayor realce o suntuosidad al altar mayor, sino que su concepción resulta acorde con la liturgia tridentina. Así, además de su manifiesto componente estético, conlleva el valor de ser el soporte de las imágenes y, por otro lado, de mostrar las enseñanzas a los fieles, aspecto en el que reside su pronunciado carácter didáctico. Debemos valorar, por tanto, cómo esta tipología responde al cambio que se impone tras la celebración del Concilio de Trento, que ejercerá una evidente influencia sobre la devoción hacia las imágenes.

Adentrándonos en esta composición debemos precisar que la obra, realizada en madera tallada y dorada, consta de un banco, de un cuerpo único de grandes dimensiones que se estructura por medio de soportes corintios $y$, finalmente, de un ático,

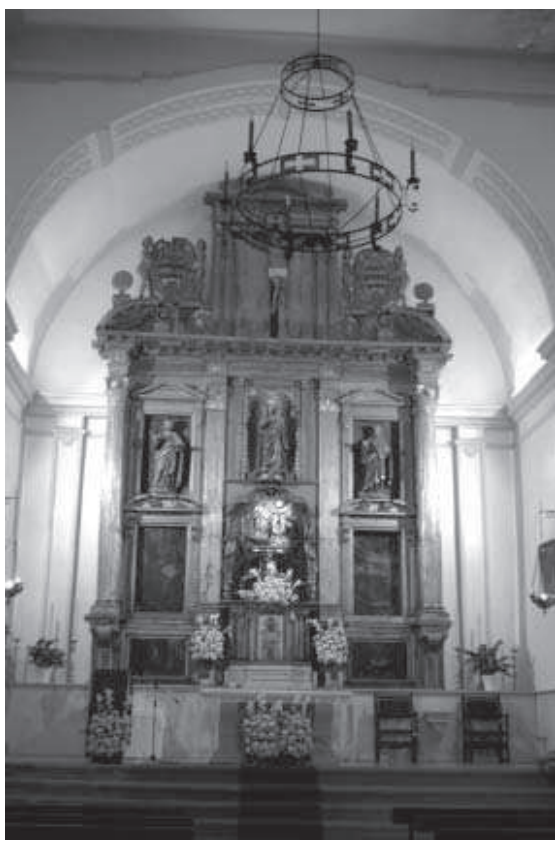

1. Retablo mayor del templo parroquial de Guadalcázar. dispuesto a modo de remate. En cuanto a la presencia de elementos constructivos debemos precisar que nos encontramos, en los extremos, ante columnas de fuste estriado en vertical con trazo inferior diferenciado. Las basas de estos soportes son áticas y se encuentran sustentadas por ménsulas voladas, mientras que los capiteles responden al esquema corintio. Sin embargo, flanqueando la calle central, por su parte, se emplazan pilastras.

Las calles laterales muestran dobles registros enmarcados por mutilos y coronados por frontones curvos, partidos en los inferiores y triangulares en el caso de los superiores. La función de estos espacios no es otra que la de albergar composiciones pictóricas y escultóricas. Por otro lado, debemos mencionar que, en este caso, tanto los soportes como los frontones mantienen la estética de otras obras coetáneas, rasgo que también se manifiesta en la ornamentación del friso y en los motivos entrelazados de las ménsulas. En la calle central, además del manifestador eucarístico, se advierte la presencia de otra hornacina, aunque se intuye que ha sido sometida a varias modificaciones. Por su parte, es el entablamento el que enmarca la zona superior de la composición, prosiguiendo los resaltes que son otorgados por los propios soportes, a excepción de la cornisa, cuyos laterales se pliegan para conformar

de la exposición. Córdoba, Diputación Provincial de Córdoba, 1986, p. 178. 




2. San Luis de Anjou.

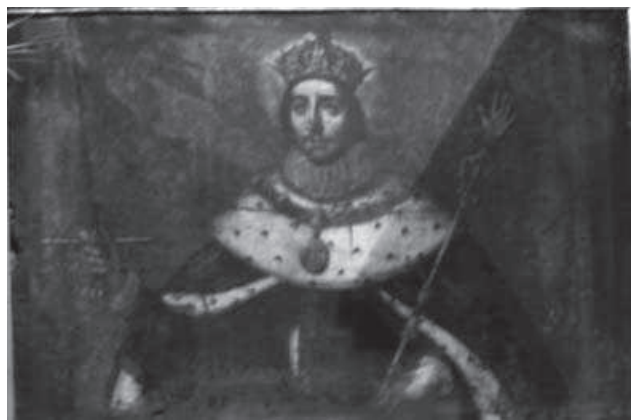

3. San Fernando.

un frontón curvo partido. En este caso, son sus extremos los que adquieren forma de roleo. Atendiendo ya a la configuración del ático detectamos la presencia de un único registro que, enmarcado por mutilos, es coronado por un pequeño frontón curvo.

Si atendemos a su lectura iconográfica observaremos que su banco aloja el tabernáculo, sobre cuya puerta se emplaza una pintura del Ecce Homo. En este caso, es flanqueado por dos lienzos en los que se representan a San Luis de Anjou ${ }^{9}$ [2] y a San Fernando ${ }^{10}$ [3]. En las calles laterales, nos encontramos ante la superposición de paneles rectangulares que guardan composiciones pictóricas, en las concavidades inferiores, e imágenes de bulto redondo, en referencia a las hornacinas superiores. Las pinturas, de derecha a izquierda, representan a Jesús Nazareno y a San

9 Se sigue el modelo impuesto por la iconografía tradicional, según el cual porta la corona en la diestra, en clara alusión a su renuncia al trono de Nápoles para poder ingresar en la orden de San Francisco.

10 La iconografía en la que es representado resulta ser de gran singularidad. De este modo, en la mano derecha porta una espada y en la izquierda un cetro terminado en una mano. Ambos atributos están presentes en la obra Selectorum Emblematum, de Gabriel Rollenhagen, donde aparecen empuñados por una mano que sale entre las nubes, aludiendo a la estrecha relación existente entre la divinidad y el príncipe. En el caso de Fernando III, existiría una referencia explícita a la tarea conquistadora como instrumento de los designios establecidos por Dios.

Con referencia a los modos de representación de la figura de San Fernando véase MORENO CUADRO, Fernando: Iconografía de San Fernando en Córdoba. Córdoba, Servicio de Publicaciones del Museo Diocesano, 1989. 
Andrés ${ }^{11}$. Con relación a las efigies escultóricas debemos precisar que no nos ha resultado posible proceder a su identificación, aunque estimamos que se trata de representaciones de apóstoles. En concreto, nos cuestionamos que bien pudieran corresponder a San Pedro y San Pablo $^{12}$, interpretación que realizamos en correspondencia al atributo que porta una de las figuras, un libro. Ya en la calle central se emplaza el manifestador eucarístico, que cuando no alberga al Santísimo Sacramento, es ocupado por las imágenes que gozan de mayor devoción en la localidad de Guadalcázar, la Virgen de la Caridad y el Crucificado de la Salud ${ }^{13}$.

Sobre el manifestador, se localiza la hornacina central que guarda una escultura de bulto redondo de María con el Niño que es identificada como Nuestra Señora de Gracia [4], a la que

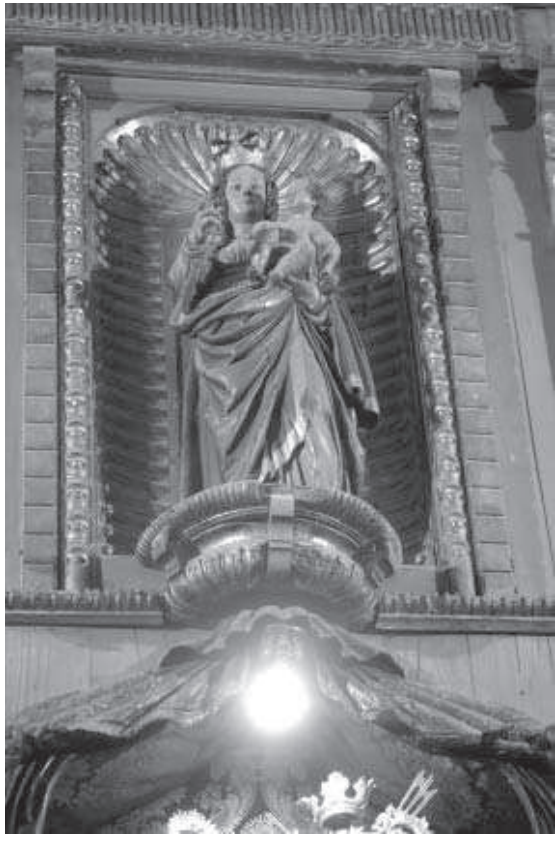

4. Nuestra Señora de Gracia. se remite la titularidad del actual templo parroquial. Su valía reside en el hecho de que responde a los criterios estéticos de las primeras décadas del XVII, es decir, al periodo denominado como protobarroco ${ }^{14}$. La serenidad de los rostros, su carácter hierático o la disposición de los ropajes en forma de curvas envolventes son algunos de los rasgos en los que nos podríamos basar para apuntar su autoría hacia círculos artísticos de ese momento. Sin lugar a dudas, la figura del Niño Jesús es la que registra un mayor interés, ya que el escultor la ha dotado de un mayor naturalismo que a la representación de su Madre. Dicha vertiente verista no sólo se manifiesta en la posición que presenta la figura, sino también, en el tratamiento realista con el que ha sido tratada su cabellera que, con bucles, viene a preludiarnos los tipos que se harán característicos en producciones como las de Juan de Mesa y Velasco.

La autoría de la Virgen de Gracia no se encuentra documentada, sin embargo, en este punto, se nos hace imprescindible detenernos en el análisis de algunos aspectos

11 Nos encontramos ante óleos sobre lienzo que, al igual que las obras escultóricas, pudieran ser fechados en el momento de ejecución del retablo, en el primer tercio del siglo XVII. Sus medidas aproximadas son de $92 \mathrm{x}$ 182 centímetros y muestran cierto estado de deterioro.

12 Ambas cuentan con una altura de 150 centímetros.

13 Se trata de una talla en madera policromada. Su altura no alcanza los 50 centímetros. Aunque actualmente la efigie se muestre enmarcada en un resplandor de estética rococó, creemos que es anterior al siglo XVII.

14 En esta imagen aún perviven las características del manierismo, de gran tradición en la provincia de Córdoba. 
concernientes a la personalidad del artista Andrés Fernánde ${ }^{15}$. Su testamento ${ }^{16}$, que data del año 1624, nos ofrece datos de gran interés con relación a la vinculación de su trabajo a la localidad de Guadalcázar y, concretamente, sobre los contactos que mantiene con don Luis Fernández de Córdoba y Portocarrero. Al parecer, Andrés Fernández no sólo intervendría en la policromía de este retablo o en la labor decorativa del palacio de los Marqueses de Guadalcázar, sino que también el entonces prelado de la diócesis malacitana le encargaría la imagen escultórica de una Virgen, a la que se alude en el mismo documento testamentario. Desgraciadamente, no existe ninguna otra referencia a esta obra, pero teniendo en cuenta los rasgos que caracterizan a la efigie de Nuestra Señora de Gracia, que corresponden estéticamente al momento al que aludimos, las primeras décadas del siglo XVII, podríamos cuestionarnos la posibilidad de que la efigie mariana fuera realizada por el propio Andrés Fernández.

Prosiguiendo con la lectura iconográfica del retablo debemos que concretar que, finalmente, en el remate, se localiza la talla de un Crucificado de origen indiano ${ }^{17}$. En esta ocasión, el Cristo es flanqueado por dos parejas de niños tenantes que sostienen el escudo del donante ${ }^{18}$, de don Luis Fernández de Córdoba y Portocarrero, como prueba plástica, y manifiesta, del patronazgo que emprende. Se desconoce el autor de las trazas, pero en este contexto, debemos valorar que en estos años se empieza a trabajar en el retablo mayor de la catedral de Córdoba $^{19}$ y que el influjo de los diseños realizados por Alonso Matías ${ }^{20}$ se dejaría sentir en la retablística contemporánea de la provincia de Córdoba ${ }^{21}$. En la misma órbita de los esquemas del jesuíta, atendiendo a sus características, el retablo mayor del templo parroquial de Nuestra Señora de Gracia de Guadalcázar ${ }^{22}$ podría ser emplazado. Así, a pesar de que no ha sido hallado ningún documento que aluda a su diseño, si que podemos detectar que el esquema que prosigue resulta deudor de las composiciones retablísticas trazadas por Alonso Matías.

Por su parte, se conoce que la talla es encomendada a los maestros Felipe Vázquez de Ureta y Juan Bautista de Botada, mientras que las labores de policromía, es decir, el dorado, estofado, las pinturas y encarnaciones, serían realizadas por artistas cordobeses Andrés Fernández y Agustín de Borja ${ }^{23}$, sustituyendo éste último al fallecido Juan Cornejo ${ }^{24}$

15 Nos referimos al padre de Felipe, Francisco Dionisio y Gaspar de Ribas, la que será una de las dinastías de artífices más importantes en el contexto de producción andaluza de la primera mitad del siglo XVII.

16 AHPC.: Protocolos notariales, oficio 29, fol. 222-236.

17 La imagen será analizada posteriormente, en referencia a la personalidad de don Diego Fernández de Córdoba y Melgarejo de Roelas, al que posiblemente se deba la presencia de esta obra en Guadalcázar.

18 Las armas son tres fajas de gules sobre oro. Resulta significativo que se recurra a la representación del escudo familiar y no al emblema episcopal de don Luis Fernández de Córdoba y Portocarrero. En este hecho, se intuye la voluntad del donante en perpetuar la memoria del grupo familiar al que pertenece.

19 Esta empresa artística es iniciada en el año 1618 bajo la protección del obispo fray Diego de Mardones.

20 Con referencia a la producción retablística del hermano jesuita véase DABRIO GONZÁLEZ, María Teresa:

"El retablo en la escuela sevillana del Seiscientos", Imafronte, n. ${ }^{\circ} 3-5$, Murcia, 1987-1989, pp.187-206.

21 Para adentrarnos en el estudio del retablo cordobés de esta época véase RAYA RAYA, María de los Ángeles: "EI retablo del siglo XVII en Córdoba", Imafronte, n. ${ }^{\circ} 3-5$. Murcia, 1987-1989, pp. 207-224.

22 RAYA RAYA, María de los Ángeles: El retablo barroco cordobés. Córdoba, Publicaciones del Monte de Piedad y Caja de Ahorros de Córdoba, 1987, p. 259

23 AHPC.: Protocolos notariales, 1618, Oficio 6, sf.

24 Nos encontramos ante la figura de uno de los pintores y doradores de mayor importancia en la ciudad de Málaga durante la etapa que comprende los últimos años del siglo XVI y los albores del XVII. Poco después de 
al que originariamente le había sido asignada esta tarea. Otra referencia es encontrada en un oficio que data del año 1620, en el que se manifiesta el compromiso por parte de Juan Bautista de Botada para la realización del segundo cuerpo y del remate del retablo ${ }^{25}$.

Contemplando el retablo con detenimiento, podemos hacer algunas observaciones $^{26}$. La primera de ellas no es otra que la inexistencia de un programa iconográfico concreto, cuyo desarrollo nos permitiría alcanzar un conocimiento más profundo de la mentalidad de la época, pero sobre todo, de la personalidad que propone el encargo. A esta apreciación añadimos otra, más elemental si cabe, y es que consideramos que las imágenes, fundamentalmente las obras escultóricas, que actualmente se disponen en el retablo no pertenecen a ese marco arquitectónico, sino que probablemente han sido añadidas a posteriori, de forma arbitraria, sin que exista testimonio del momento en el que se producen esos cambios. En este caso, dicho traslado de imágenes, nos ha impedido conocer los asuntos iconográficos que habían sido seleccionados por el donante de la obra, por don Luis Fernández de Córdoba. Por su parte, estas modificaciones también se insinúan al observar que su estructura parece haber sido rehecha, ya que por ejemplo, en la zona central, quizás se ubicaban unas columnas que actualmente han desaparecido. De todo modos, nuestro planteamiento acerca de las alteraciones que pudieron producirse en este retablo no sólo se sustenta en apreciaciones visuales, sino también en el conocimiento de que, en mayo del año 1622, el pintor Agustín de Castillo se compromete con el obispo de Málaga a realizar una serie de lienzos destinados al retablo mayor del templo parroquial de Guadalcázar ${ }^{27}$. Pese a contar con esta noticia, no se conocen más datos sobre estas obras y actualmente se ignora su paradero.

incorporarse a su labor en Guadalcázar se produce su fallecimiento.

Por su parte, el padre Llordén Simón, a través de unos documentos a los que accede sin concretar su procedencia, nos da a conocer información relativa a los avatares de este encargo: "En la ciudad de Málaga en 21 de diciembre de 1621 su señoría IIma. Sr. Luis Fernández de Córdoba, obispo de Málaga, del Consejo de S. Majestad, y Diego de Salinas, como albacea y testamentario de Juan Cornejo, pintor y dorador, dijeron que es así que el dicho Juan Cornejo tenía a su cargo dorar el retablo de la iglesia parroquial de Guadalcázar, en lo cual estaba entendido por mandado y orden del dicho Sr. Obispo y por su cuenta, y porque el dicho Juan Cornejo murió poco ha en la dicha villa de Guadalcázar y es necesario averiguar cuenta de lo que tenía recibido y se le debe por razón de las dichas obras, las cuales estaban concertadas de esta manera, que por así de oro como aparejos y manos se le había de dar y pagar a razón de 160 reales por millar, y los millares que hubieren entregado, por tanto, para que lo suso dicho tenga efecto, su Señoría por su parte nombró por tasador a Andrés Fernández, pintor y dorador, vecino de la ciudad de Córdoba, y Diego de Salinas por su parte nombró a Agustín de Borja, asimismo pintor y dorador, vecino de la misma ciudad, para que juntos vayan a Guadalcázar que hagan ante la justicia de la dicha villa, tasen la obra, conforme a lo arriba referido, y lo que montan los panes de oro... Para que conforme a ello se haga la monta y pago con el dicho Juan Cornejo ante la dicha justicia y escribano público que de fe..." en LLORDÉN SIMÓN, Andrés: Pintores y doradores malagueños. Ensayo histórico-documental de los siglos XVI- XIX. Ávila, El Escorial, 1959, p. 100.

25 AHPC.: Protocolos notariales, 1620, Oficio 4, Vol. 78, fols. 167 y ss.

26 AHPC.: Protocolos notariales, 1620, Oficio 4, Vol. 78, fols. 167 y ss

27 RAYA RAYA, María de los Ángeles.: Catálogo de las pinturas de la Catedral de Córdoba. Córdoba, Publicaciones del Monte de Piedad y Caja de Ahorros de Córdoba, 1987, p. 41. 
